\title{
PENGARUH VIRTUALISASI LABORATORIUM BERBASIS ELECTRONICS WORKBENCH (EWB) PADA MATA KULIAH ELEKTRONIKA DASAR UNSRIT
}

\author{
Meidy Kuron'1), Arnold Umboh'1) \\ 1)Program Studi Teknik Informatika Universitas Sariputra Indonesia Tomohon \\ Corresponding author : Meidy Kuron \\ E-mail : Meidykuron@unsrittomohon.ac.id
}

\section{Diterima 21 September 2020, Direvisi 06 November 2020, Disetujui 08 November 2020}

\begin{abstract}
ABSTRAK
Penggunaan laboratorium virtual pada mata kuliah Elektronika Dasar sangatlah penting sebagai salah satu solusi mengatasi keterbatasan fasilitas pada laboratorium real di Universitas Sariputra Indonesia Tomohon. Virtualisasi laboratorium Elektronika Dasar ini dapat berfungsi selayaknya laboratorium real yang memanfaatkan media komputer dan software Electronics Workbench (EWB) dalam pembelajaran. Tujuan khusus penelitian ini adalah mengetahui pengaruh virtualisasi laboratorium berbasis Electronics Workbench (EWB) terhadap hasil belajar mahasiswa semester II Program Studi Teknik Informatika pada mata kuliah Elektronika Dasar di Universitas Sariputra Indonesia Tomohon. Metode yang digunakan adalah Pre-Eksperiment One-Group Pretest-Posttest Design dengan pengujian analisis paired sample t-test dengan sample penelitian diambil total sampling. Hipotesis penelitian dianalisis dengan bantuan aplikasi SPSS untuk memperoleh $\mathrm{t}$ hitung dengan taraf kepercayaan $95 \%$ dimana $\mathrm{t}$ hitung $>t$ tabel yaitu 19,126 > 2,055 dan berdasarkan nilai signifikansi yaitu Sig. (2-tailed) 0,000<0,05 dapat disimpulkan terdapat pengaruh yang signifikan virtualisasi laboratorium berbasis EWB terhadap hasil belajar mahasiswa Teknik Informatika UNSRIT Semester II materi Elektronika Dasar materi penguat transistor. Selanjutnya dilakukan pengujian N-Gain score untuk melihat efektivitas penggunaan virtualisasi laboratorium berbasis EWB dalam meningkatkan hasil belajar mahasiswa Teknik Informatika UNSRIT dengan hasil 0,40 termasuk pada kategori sedang. Luaran yang ditargetkan dalam penelitian ini diharapkan dapat dipublikasikan pada jurnal Nasional terakreditasi SINTA 4 Jurnal Kajian, Inovasi dan Aplikasi Pendidikan Fisika p-ISSN : 2460-9587, i-SSN : 2614-7017 Program Studi Pendidikan Fisika Fakultas Keguruan dan Ilmu Pendidikan Universitas Muhamadiyah Mataram.
\end{abstract}

Kata kunci : virtualisasi laboratorium; electronics workbench (EWB); elektronika dasar.

\begin{abstract}
The use of virtual laboratories of the Basic Electronics courses is very important as a solution to overcome the limited facilities in real laboratories at Sariputra Indonesia University, Tomohon. Virtualization of the Basic Electronics laboratory can function like a real laboratory that utilizes computer media and the Electronics Workbench (EWB) software in learning. The specific purpose of this study was to determine the effect of laboratory virtualization based on Electronics Workbench (EWB) on the learning outcomes of second semester students of the Informatics Engineering Study Program in Basic Electronics at Sariputra Indonesia University, Tomohon. The method used is the Pre-Experiment OneGroup Pretest-Posttest Design with paired sample t-test analysis testing with the research sample taken by total sampling. The research hypothesis was analyzed with the SPSS application to obtain t count with a confidence level of $95 \%$ where $t$ count $>t$ table, that result 19,126 $>2,055$ and based on the significance value of Sig. (2-tailed) $0.000<0.05$, it can be concluded that there is a significant effect of based laboratory virtualization based on EWB to students learning outcomes of Informatics Engineering UNSRIT Semester II Basic Electronics material transistor amplifier. Furthermore, the N-Gain score test was carried out to see the effectiveness of using laboratory virtualization based on EWB to improving the learning outcomes of UNSRIT Informatics Engineering students with a result of 0.40 which was included in the moderate category. The output targeted in this study is expected to be published in a SINTA-accredited National journal 4 Journal of Study, Innovation and Physics Education Application pISSN: 2460-9587, i-SSN: 2614-7017 Study Program of Physics Education, Faculty of Teacher Training and Education, Muhamadiyah University, Mataram.
\end{abstract}

Keywords : virtual laboratories; electronics workbench (EWB); basic electronics. 


\section{PENDAHULUAN}

Laboratorium adalah sarana yang sangat penting dan tidak dapat dipisahkan dari suatu proses pendidikan. Peningkatan kualitas pendidikan dijenjang pendidikan formal tidak lepas dari sumber daya tenaga pendidik, fasilitas belajar termasuk sarana dan prasarana yang mendukung proses perkuliahan agar tercapai tujuan pembelajaran yang maksimal. Sehubungan kaitan antara teori dan praktek, maka sangat penting kualitas pelayanan laboratorium komputer terhadap peningkatan kemampuan belajar mahasiswa (Panjaitan, 2015).

Sarana dan prasarana termasuk gedung /ruang belajar, gedung laboratorium, gedung perpustakaan, gedung/lapangan olahraga serta fasilitas didalamnya sangat menunjang dan mendukung kegiatan perkuliahan. Fasilitas yang memadai ditambah skill yang baik dari pendidik akan menghasilkan kualitas belajar mengajar yang baik pula serta luaran yang dihasilkan berkualitas baik kognitif dan motoriknya. Khususnya dalam penelitian ini ditekankan pada fasilitas laboratorium elektronika dasar pada objek penelitian yang masih belum memadai untuk menunjang kegiatan perkuliahan. Laboratorium sendiri adalah tempat untuk melakukan berbagai manipulasi percobaan, baik bersifat pembuktian (verificative) maupun penemuan (discovery) yang dilakukan oleh orang-orang tertentu dalam mencapai tujuan (Wiratma, 2014).

Kendala yang dihadapi instansi pendidikan dalam menyediakan sarana dan prasarana yang lebih memadai adalah biaya yang tidak sedikit serta jangka waktu yang cukup lama. Menyediakan suatu laboratorium seperti lab-Elektro, lab-Fisika, lab-Komputer, lab-Keperawatan, lab-Kimia, lab-Farmasi dan lain sebagainya bukanlah sesuatu yang mudah untuk diselenggarakan dalam jangka waktu yang singkat serta membutuhkan dana yang banyak.

Beberapa mata kuliah tidaklah lengkap tanpa disertai dengan kegiatan praktikum seperti yang dilakukan di laboartorium pada umumnya bahkan beberapa mahasiswa berpendapat bahwa dengan kegiatan praktikum, pembelajaran lebih cepat dipahami termasuk aplikasi dalam kehidupan sehari-hari terasa lebih nyata. Rata-rata hasil belajar mahasiswa pada mata kuliah Elektronika Dasar tahun akademik genap 2018-2019 hanya mencapai 45,00-50,00 sebelum digunakan laboratorium virtual berbasis EWB. Berdasarkan hasil observasi yang dilakukan di Universitas Sariputra Indonesia Tomohon mengenai ketersediaan sarana dan prasarana lebih khusus laboratorium Elektronika Dasar didapati masih belum memadai untuk menunjang kegiatan perkuliahan di Kampus tersebut. Dalam kurikulum yang digunakan di Fakultas Teknik terdapat mata kuliah antara lain fisika dasar dan elektronika dasar yang dalam proses perkuliahan membutuhkan fasilitas laboratorium elektronika serta komponen di dalamnya seperti dioda, transistor, FET, OPAMP dan lain sebagainya.

Keberadaan laboratorium elektronika dasar yang kurang memadai ini dapat mengakibatkan terganggunya proses perkuliahan yang baik terlebih kurangnya kepuasan mahasiswa terhadap hasil belajarnya. Salah satu solusi adalah laboratorium virtual yang digunakan untuk meningkatkan kompetensi siswa sekolah kejuruan dalam arti kognitif, psikomotor, dan karakter siswa (Jaya, 2012). Sebuah penelitian mengungkapkan bahwa penerapan pembelajaran dengan model lab virtual $P h E T$ pada teori kinetik gas mengalami kenaikan hasil belajar 85,42\% (Rizal Bagus Syaifulloh, 2014).

Penggunaan laboratorium virtual dapat menjadi alternatif pertimbangan dalam menanggulangi ketidaktersediaannya laboratorim elektronika dasar di Universitas Sariputra Indonesia Tomohon yaitu dengan memanfaatkan software Electronics Workbench (EWB) dalam proses perkuliahan. Berdasarkan hal tersebut diatas maka penelitian ini dipandang perlu dilakukan untuk mengetahui seberapa besar pengaruh penggunaan virtualisasi laboratorium berbasis Electronics Workbench (EWB) terhadap hasil belajar mahasiswa pada mata kuliah Elektronika Dasar semester II Teknik Informatika Universitas Sariputra Indonesia Tomohon. Hasil penelitian ini digunakan untuk menunjang dan mendukung proses perkuliahan lebih efektif dengan hasil belajar mahasiswa yang lebih maksimal.

\section{METODE PENELITIAN}

Metode yang digunakan dalam penelitian ini adalah metode Pre-Experimental Design dimana hasil dari variabel dependen dalam penelitian pre-experimental bukan semata-mata dipengaruhi oleh variabel independen melainkan masih terdapat variabel luar yang mempengaruhi disebabkan karena tidak adanya variabel kontrol dan sampel tidak dipilih secara random (Sugiyono, 2012). Salah satu desain penelitian pre-experimental adalah One-Group Pretest-Posttest Design yang digunakan dalam penelitian ini. Adapun desain penelitian One-Group Pretest-Posttest dapat dilihat pada tabel 1. 
Tabel 1. Desain penelitian One-Group Pretest-Posttest

\begin{tabular}{ccc}
\hline Pretest & Treatment & Posttest \\
\hline $\mathrm{O}_{1}$ & $\mathrm{X}$ & $\mathrm{O}_{2}$ \\
\hline
\end{tabular}

Sumber: (Sugiyono, 2012).

Penelitian ini dilakukan di Universitas Sariputra Indonesia Tomohon dengan subjek penelitian mahasiswa semester II Prodi Teknik Informatika dengan mata kuliah Elektronika Dasar khususnya materi penguat transistor common base dan common emitter. Berdasarkan Kurikulum yang digunakan di Program Studi Teknik Informatika UNSRIT untuk mata kuliah Elektronika Dasar hanya diajarkan pada semester genap dan tidak dibagi menjadi Elektronika Dasar 1 dan Elektronika Dasar 2. Penelitian dilakukan pada bulan Januari tahun 2020 sampai bulan Juli tahun 2020 pada semester genap tahun Akademik 2019-2020. Teknik pengumpulan data yang digunakan yaitu melalui pretest hasil belajar mahasiswa sebelum digunakan laboratorium virtual berbasis software EWB dan posttest hasil belajar mahasiswa setelah digunakan laboratorium virtual berbasis software EWB pada mata kuliah Elektronika Dasar materi rangkaian penguat transistor.

Alat ukur yang digunakan untuk menguji hasil belajar mahasiswa terlebih dahulu diuji tingkat kelayakannya agar benar-benar valid dan reliabel. Sampel penelitian diambil dengan cara total sampling dengan melihat jumlah mahasiswa pada Prodi Teknik Informatika UNSRIT tahun akademik 2019-2020 sebanyak 27 orang mahasiswa dan hipotesis penelitian menggunakan uji paired-samples t-tes yang merupakan analisis dengan melibatkan dua pengukuran pada subjek yang sama terhadap suatu pengaruh atau perlakukan tertentu. Adapun hipotesis penelitian adalah sebagai berikut :

Ho $=\mu_{1} \leq \mu_{2}$ : "Tidak terdapat pengaruh virtualisasi laboratorium berbasis EWB terhadap hasil belajar mahasiswa.

$\mathbf{H}_{\mathbf{1}}=\boldsymbol{\mu}_{\mathbf{1}}>\boldsymbol{\mu}_{\mathbf{2}}$ : "Terdapat pengaruh virtualisasi laboratorium berbasis EWB terhadap hasil belajar mahasiswa.

\section{HASIL DAN PEMBAHASAN Hasil Penelitian}

Penelitian ini dilakukan sebanyak 4 kali pertemuan dimana pertemuan I dan II diajarkan materi Elektronika Dasar tentang rangkaian penguat transistor common base dengan kuliah mimbar metode ceramah sekaligus diberikan prettes. Pertemuan III dan IV diajarkan materi Elektronika Dasar tentang rangkaian penguat transistor common emitter dengan menggunakan software Electronics Workbench (EWB) sekaligus dilakukan posttest. Adapun rangkaian penguat transistorcomment Emmiter menggunakan software Electronics Workbench (EWB).

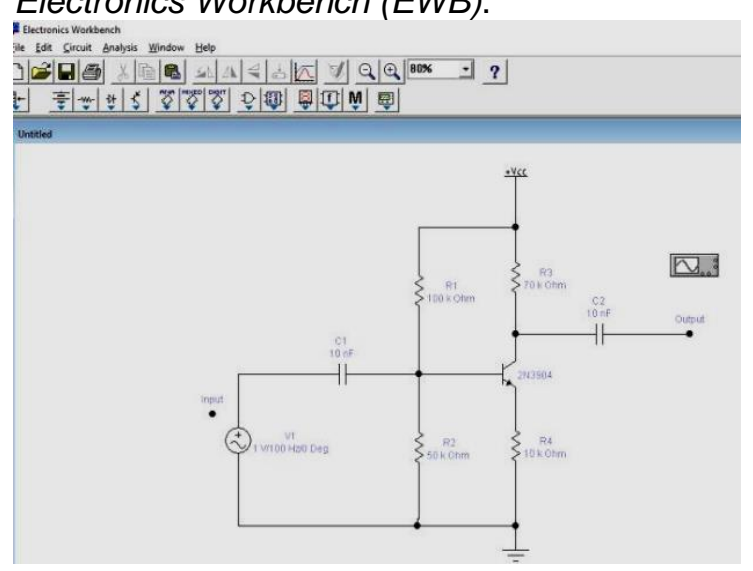

Gambar 1. Rangkain penguat transistor comment Emmiter

Deskripsi data statistik pada analisis data hasil belajar mahasiswa tahun akademik ganjil 2019-2020 terdapat pada tabel 2.

Tabel 2. Deskripsi statistik hasil belajar mahasiswa

\begin{tabular}{|c|c|c|c|c|c|c|c|c|}
\hline \multicolumn{9}{|c|}{ Descriptive Statistics } \\
\hline & $\mathrm{N}$ & Range & $\begin{array}{l}\text { Minim } \\
\text { um }\end{array}$ & $\begin{array}{c}\text { Maxim } \\
\text { um }\end{array}$ & Sum & Mean & $\begin{array}{c}\text { Std. } \\
\text { Deviation }\end{array}$ & $\begin{array}{c}\text { Varia } \\
\text { nce }\end{array}$ \\
\hline Pretest & 27 & 35.0 & 30.00 & 65.00 & 1310.0 & 48.51 & 10.26 & 105.4 \\
\hline Posttest & 27 & 30.0 & 55.00 & 85.00 & 1860.0 & 68.88 & 9.43 & 89.10 \\
\hline $\begin{array}{l}\text { Valid N } \\
\text { (listwise) }\end{array}$ & 27 & & & & & & & \\
\hline
\end{tabular}

Deskripsi hasil belajar mahasiswa pada mata kuliah Elektronika Dasar Semester II Program Studi Teknik Informatika Fakultas Teknik UNSRIT yang dibagi atas Pretest dan Posttest adalah sebagai berikut: Jumlah mahasiswa semester II adalah 27 orang maka $\mathrm{N}=27$ dengan rata-rata pretest dan posttest masingmasing 48,51 dan 68,89 sedangkan nilai terendah pada pretest adalah 30 dan pada posttest adalah 55 sedangkan nilai tertinggi pada pretest adalah 65 dan pada posttest adalah 85 dengan total nilai pretest adalah 1.310 dan posttest adalah 1.860 . 
Histogram

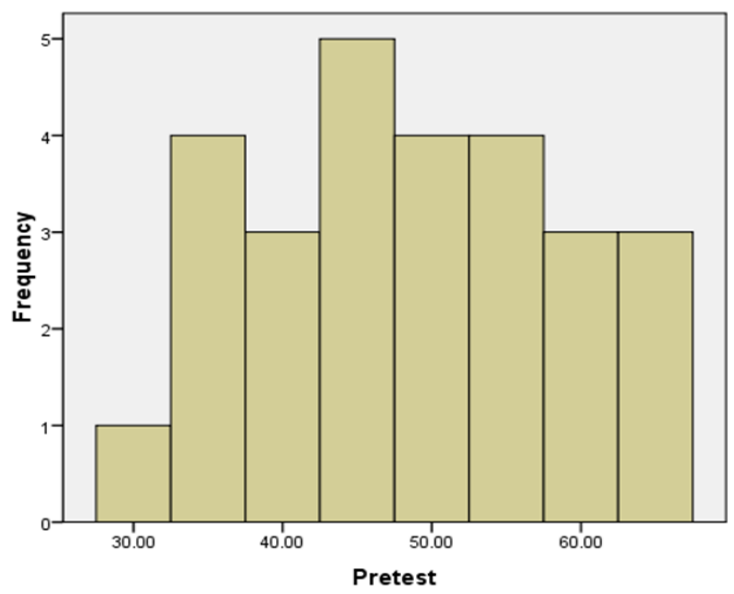

Gambar 2. Histogram data pretest

Histogram

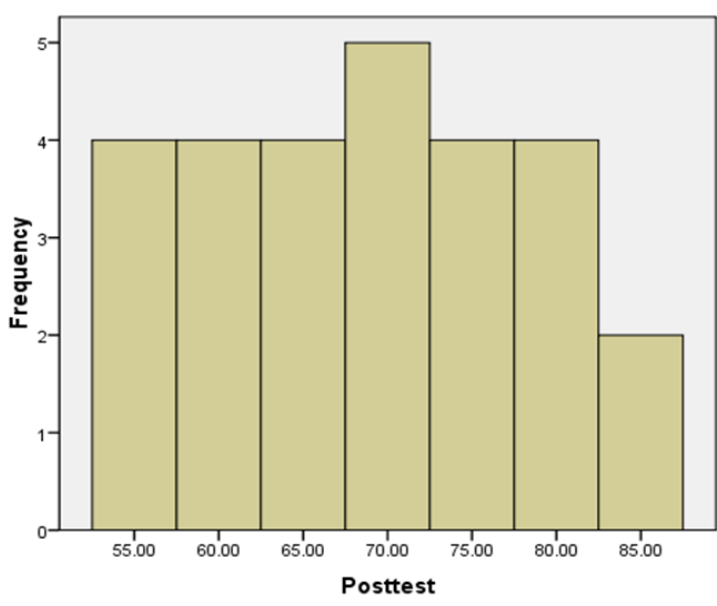

Gambar 3. Histogram data posttest

Pengujian hipotesis menggunakan uji paired sample t-test dimana terdapat syarat yang harus dipenuhi terlebih dahulu yaitu perbedaan dua kelompok data berdistribusi normal maka harus dilakukan uji terlebih dahulu dengan uji normalitas pada perbedaan kedua kelompok tersebut. Dalam penelitian ini, uji normalitas menggunakan uji Shapiro-Wilk berbantuan SPSS dengan dasar pengambilan keputusan nilai signifikansi $>0,05$ maka terima $\mathrm{Ha}$ dan tolak Ho dimana data berdistribusi normal.

\begin{tabular}{lrrrrrr}
\hline \multicolumn{7}{c}{ Tabel 3. Uji Normalitas } \\
\hline \multicolumn{7}{c}{ Tests of Normality } \\
\hline Kolmogorov-Smirnov & \multicolumn{3}{c}{ Shapiro-Wilk } \\
\hline Statistic & Df & Sig. & Statistic & df & Sig. \\
\hline Pretest & .116 & 27 & $.200^{*}$ & .950 & 27 & 217 \\
\hline Posttest & .123 & 27 & $.200^{*}$ & .937 & 27 & .103 \\
\hline
\end{tabular}

a. Lilliefors Significance Correction

*. This is a lower bound of the true significance.
Tabel 3. Tests of Normality diatas diperoleh data pretest pengujian normalitas KolmogorovSmirnov $v^{a}$ nilai signifikansi $0,200>0,05$ dan Shapiro-Wilk nilai signifikansi $0,217>0,05$ sedangkan untuk posttest pengujian normalitas Kolmogorov-Smirnov ${ }^{a}$ nilai signifikansi 0,200 >0,05 dan Shapiro-Wilk nilai signifikansi $0,103>0,05$ dengan demikian kedua data pretest dan posttest adalah berdistribusi normal selanjutnya dilakukan uji hipotesis. Hipotesis dalam penelitian ini diuji menggunakan analisis paired sample t-test berbantuan SPSS.

Tabel 4. Paired sample statistic T-Test

\begin{tabular}{|c|c|c|c|c|c|}
\hline \multicolumn{6}{|c|}{ Paired Samples Statistics } \\
\hline & & Mean & $N$ & $\begin{array}{c}\text { Std. } \\
\text { Deviation }\end{array}$ & $\begin{array}{l}\text { Std. Error } \\
\text { Mean }\end{array}$ \\
\hline \multirow{2}{*}{$\begin{array}{l}\text { Pair } \\
1\end{array}$} & Pretest & 48.51 & 27 & 1026 & 1.97 \\
\hline & Posttest & 68.88 & 27 & 9.43 & 1.81 \\
\hline
\end{tabular}

Interpretasi tabel 4. Paired sample statistic ini menunjukkan data statistik dari penelitian yang telah dilakukan dimana jumlah sampel $\mathrm{N}=27$, rata-rata dari pretest dan posttest masingmasing 48,51 dan 68,88 serta standar deviasi kedua data menunjukkan 10,26 dan 9,43.

Tabel 5. Paired sample Correlations

\begin{tabular}{lcccc}
\hline \multicolumn{5}{c}{ Paired Samples Correlations } \\
\hline & & N & Correlation & Sig. \\
\hline Pair 1 & Pretest \& Posttest & 27 & .846 & .000 \\
\hline
\end{tabular}

Tabel 5. Paired sample Correlations menunjukkan bahwa nilai korelasi antara 2 variabel tersebut hasilnya 0,846 dengan sig. $0,000<$ probabilitas 0,05 yang artinya terdapat hubungan kuat dan positif antara variabel pretest dan posttest yang diteliti.

Tabel 6. Paired sample test

\begin{tabular}{|c|c|c|c|c|c|c|c|c|}
\hline \multicolumn{9}{|c|}{ Paired Samples Test } \\
\hline & \multicolumn{5}{|c|}{ Paired Differences } & \multirow[b]{3}{*}{$\mathrm{t}$} & \multirow{3}{*}{ df } & \multirow{3}{*}{$\begin{array}{l}\text { Sig. (2- } \\
\text { tailed) }\end{array}$} \\
\hline & \multirow{2}{*}{ Mean } & \multirow{2}{*}{$\begin{array}{l}\text { Std. } \\
\text { Deviati } \\
\text { on }\end{array}$} & \multirow{2}{*}{$\begin{array}{l}\text { Std. } \\
\text { Error } \\
\text { Mean }\end{array}$} & \multicolumn{2}{|c|}{$\begin{array}{l}95 \% \text { Confidence } \\
\text { Interval of the } \\
\text { Difference } \\
\end{array}$} & & & \\
\hline & & & & Lower & Upper & & & \\
\hline $\begin{array}{r}\text { Pair } 1 \text { Pretest - } \\
\text { Posttest }\end{array}$ & -20.37 & 5.53 & 1.06 & -22.55 & -18.18 & -19.12 & 26 & .000 \\
\hline
\end{tabular}

Tabel 6. Paired sample test adalah output terpenting dari pengujian ini sebab pada bagian ini hipotesis penelitian terjawab.

$\mathrm{H}_{0}=$ "Tidak terdapat pengaruh virtualisasi laboratorium berbasis EWB terhadap hasil belajar mahasiswa."

$\mathrm{Ha}=$ "Terdapat pengaruh virtualisasi laboratorium berbasis EWB terhadap hasil belajar mahasiswa."

Pedoman pengambilan keputusan dalam uji paired sample t-test (Santoso, 2014) 
berdasarkan nilai signifikansi output SPSS sebagai berikut :

Sig. (2-tailed) $<0,05$ maka $\mathrm{H}_{0}$ ditolak dan $\mathrm{Ha}$ diterima

Sig. (2-tailed) >0,05 maka $\mathrm{H}_{0}$ diterima dan $\mathrm{Ha}$ ditolak

Berdasarkan Tabel 6. Paired sample test menunjukkan bahwa nilai Sig. (2-tailed) adalah sebesar $0,000<0,05$ maka $\mathrm{H}_{0}$ ditolak dan $\mathrm{Ha}$ diterima sehingga dapat disimpulkan bahwa terdapat pengaruh virtualisasi laboratorium berbasis EWB terhadap hasil belajar mahasiswa. Selanjutnya, membandingkan nilai $t$ hitung dengan $t$ tabel dengan dasar pengambilan keputusan sebagai berikut :

Jika t hitung $>\mathrm{t}$ tabel maka $\mathrm{H}_{0}$ ditolak dan $\mathrm{Ha}$ diterima

Jika t hitung $<\mathrm{t}$ tabel maka $\mathrm{H}_{0}$ diterima dan Ha ditolak

Tabel 6 Paired sample test diperoleh t hitung adalah $-19,126$ bernilai negatif disebabkan karena nilai rata-rata hasil belajar pretest lebih rendah daripada rata-rata hasil belajar pada posttest. Dalam hal ini, dapat dikatakan bahwa $t$ hitung yang bernilai negative dapat bermakna positif 19,126. Berdasarkan tabel Paired sample test diketahui nilai $d f$ (degree of freedom) atau derajat kebebasan adalah 26 dengan nilai signifikansi $(\alpha / 2)$ yaitu $0,05 / 2$ adalah 0,025 . Informasi data tersebut digunakan sebagai acuan dalam menentukan t tabel pada tabel distribusi t statistik yaitu sebesar 2,055.

Dengan demikian nilai $t$ hitung $>t$ tabel yaitu 19,126 > 2,055 disimpulkan bahwa terima $\mathrm{Ha}$ dan tolak $\mathrm{H}_{0}$ dimana terdapat pengaruh virtualisasi laboratorium berbasis EWB terhadap hasil belajar mahasiswa Teknik Informatika UNSRIT khususnya pada mata kuliah Elektronika Dasar.

Selanjutnya adalah mencari seberapa besar efektivitas penggunaan laboratorium virtual berbasis EWB dalam meningkatkan hasil belajar mahasiswa Teknik Informatika UNSRIT dengan menggunakan uji Normalized Gain atau lebih dikenal uji $\mathrm{N}$-Gain. Adapun rumus yang digunakan untuk menghitung $\mathrm{N}$-Gain Score seperti dibawah ini :

Normalized Gain $(g)$ $=\frac{\text { Posttest Score }- \text { Pretest Score }}{\text { Max Score }- \text { Prettest Score }}$
Tabel 7. Kategori Normalized Gain Score

\begin{tabular}{cc}
\hline $\begin{array}{c}\text { Normalized Gain } \\
\text { Score }\end{array}$ & Kategori \\
\hline $\mathrm{g}>0,7$ & Tinggi \\
\hline $0,3 \leq \mathrm{g} \leq 0,7$ & Sedang \\
$\mathrm{g}<0,3$ & Rendah
\end{tabular}

Sumber : (Hake dan Richard, 2002)

Dalam penelitian ini pengujian $\mathrm{N}$-Gain dibantu dengan Microsoft Excel sebagai berikut :

$$
\begin{aligned}
\text { Normalized Gain }(g) & =\frac{68,89-48,52}{100-48,52} \\
& =\frac{20,37}{51,48}=0,40
\end{aligned}
$$

Berdasarkan hasil Nornalized Gain Score adalah 0,40 dicocokkan dengan tabel 8 kategori Normalized Gain Score dapat simpulkan bahwa terdapat pengaruh yang signifikan virtualisasi laboratorium berbasis EWB terhadap hasil belajar mahasiswa Teknik Informatika UNSRIT pada kategori sedang.

\section{Pembahasan}

Perkuliahan Elektronika Dasar perlu ditunjang dengan virtualisasi laboratorium berbasis software Electronics Workbench (EWB) yang melalui hasil penelitian ini terdapat pengaruh positif terhadap hasil belajar mahasiswa. Hal ini juga memberikan pandangan dan motivasi yang lebih baik bagi pendidik dalam hal ini dosen agar dapat memanfaatkan laboratorium virtual berbasis Electronics Workbench (EWB) dalam pelaksanaan pembelajaran lebih khusus praktikum pada mata kuliah Elektronika Dasar semester II Teknik Informatika Fakultas Teknik UNSRIT. Sejalan dengan dasar teori laboratorium virtual diperlukan untuk memperkuat pemahaman konsep dalam proses pembelajaran, namun bukan merupakan pengganti laboratorium real tetapi sebagai bagian dari laboratorium real yang digunakan untuk melengkapi dan memperbaiki keterbatasan yang ada (Widhy, 2010). Untuk itu laboratorium virtual dapat mengatasi masalah dan kesulitan yang dihadapi pada saat menggunakan laboratorium real seperti terbatasanya alat dan bahan, mahalnya biaya peralatan laboratorium real, mempersingkat waktu, meminimalisir kerusakan alat, arus pendek, dan lain sebagainya. Hal ini dipandang positif sebab sehari-hari mahasiswa pada

Program Studi Teknik Informatika tidak lepas dari peralatan komunikasi termasuk komputer, maka tidak susah bagi mereka untuk dapat menggunakan Electronics Workbench (EWB) dalam pembelajaran 
Elektronika Dasar. Apabila mahasiswa telah terbiasa menggunakan laboratorium virtual berbasis EWB dalam pembelajaran maka mahasiswa tidak akan merasa kesulitan dalam menyelesaikan rangkaian elektronika lain yang lebih rumut dari rangkaian penguat transistor. Hal ini dapat membuat mahasiswa lebih percaya diri, berani dan terampil dalam mengenali komponen-komponen elektronika terlebih dapat meningkatkan hasil belajar mahasiswa.

Sejalan dengan beberapa penelitian mengemukakan bahwa terdapat pengaruh yang signifikan pemanfaatan laboratorium virtual berbasis electronics workbench (EWB) untuk menunjang pemahaman konsep mahasiswa pada perkuliahan Elektronika Dasar I di Universitas Muhamadiyah Mataram (Islahudin, 2019). Hasil penelitian lain menunjukkan terjadi peningkatan penguasaan konsep siswa pembelajaran discovery berbantuan laboratorium virtual (Sari, 2016) dan penelitian pada mahasiswa Program Studi Teknik Komputer UNSRIT mengemukakan bahwa pembelajaran mahasiswa lebih maksimal dan respon positif mahasiswa terhadap penggunaan laboratorium komputer dalam pembelajaran (Kuron, 2019).

\section{SIMPULAN DAN SARAN Simpulan}

Berdasarkan hasil penelitian maka dapat disimpulkan bahwa virtualisasi laboratorium berbasis Electronics Workbench (EWB) pada materi Elektronika Dasar berpengaruh signifikan terhadap hasil belajar mahasiswa semester II Program Studi Teknik Informatika Fakultas Teknik UNSRIT. Mahasiswa semester II Teknik Informatika menunjukkan peningkatan rata-rata hasil belajar melalui pretest dan posttest dengan pengujian paired sample t-test. Hasil penelitian ini dapat menjadi acuan dan referensi bagi pendidik untuk dapat menerapkan pembelajaran menggunakan virtualisasi laboratorium berbasis Electronics Workbench (EWB)

\section{Saran}

Berdasarkan hasil penelitian maka diisarankan bagi pendidik agar dapat memanfaatkan virtualisasi laboratorium berbasis Electronics Workbench (EWB) dalam pembelajaran lebih khusus pada materi Elektronika Dasar agar kemampuan belajar mahasiswa dari segi kognitif maupun psikomotor lebih efektif dan meningkat. Saran bagi mahasiswa agar lebih mengembangkan keterampilan belajar mandiri dengan memanfaatkan virtualisasi laboratorium berbasis Electronics Workbench (EWB) sebab penggunaannya sangat mudah.

\section{DAFTAR RUJUKAN}

Hake dan Richard, R., (2002). Relationship of Individual student Normalized learn Gains in Mechanics with Gender, HighSchool Physics, and Pretest scores on Mathematics and Spatial Visualization. s.l.:s.n.

Islahudin, M. I., (2019). Pemanfaatan Laboratorium Virtual Berbasis Software Electronics Workbench (EWB) Untuk Menunjang Pemahaman Konsep Mahasiswa Pada Mata Kuliah Elektronika Dasar I. E-Jurnal ORBITA: Jurnal Hasil Kajian Inovasi dan Aplikasi Pendidikan Fisika p-ISSN 2460-9587, eISSN 2614-7017, Volume 5, p. 2.

Islahudin, I., Sabaryati, J., Zulkarnain, Z., \& Soeharto, S. (2020). Design of Work Instruction (WI) Electronic WorkbenchAssisted Electrical Measuring Devices to Improve the Internship Concept of Students in Basic Electronic II Course. JIPF (Jurnal IImu Pendidikan Fisika). https://doi.org/10.26737/jipf.v5i2.1722

Jaya, H., (2012). Pengembangan laboratorium virtual untuk kegiatan praktikum dan memfasilitasi pendidikan karakter di SMK. Jurnal Pendidikan Vokasi E-ISSN 2476-9401; P-ISSN 2088-2866, Volume 2, p. 1 .

Kuron, M., (2019). Pengaruh Penggunaan Laboratorium Komputer Terhadap Hasil Belajar Mahasiswa Teknik Komputer UNSRIT. E-Jurnal Sariputra Jurnal IImuIImu Multidisiplin, Volume 6, p. 3.

Panjaitan, (2015). Analisis tingkat kepuasan mahasiswa terhadap kualitas pelayanan Laboratorium Komputer Universitas Bina Darma. SNIT, Volume 1, p. 1.

Rizal Bagus Syaifulloh, B. J., (2014). Penerapan Pembelajaran dengan Model Guided Discovery dengan Lab Virtual PhET Untuk Meningkatkan Hasil Belajar Siswa Kelas XI Di SMAN 1 Tuban Pada Pokok Bahasan Teori Kinetik Gas. Jurnal Inovasi Pendidikan Fisika (JIPF) 174-179 ISSN: 23024496., Volume 3, p. 2.

Santoso, S., (2014). Statistik Parametrik Edisi Revisi. Jakarta: Elex Media Komputindo.

Sari, P. I. G. G. H. A., (2016). Penggunaan Discovery Learning Berbantuan Laboratorium Virtual pada Penguasaan Konsep Fisika Siswa. Jurnal Pendidikan Fisika dan Teknologi e-ISSN: 24076902 \& p-ISSN: 2614-5618, Volume 2, p. 4. 
Sugiyono, (2012). Metode Penelitian Pendidikan pendekatan kuantitatif. Yogyakarta: Alfabeta.

Widhy, P., (2010). Pemanfaatan Laboratorium Virtual Pada Pembelajaran IPA Pelatihan digitalisasi.

Wiratma, G. L. d., (2014). Pengelolaan Laboratorium Kimia Pada SMA Negeri di Kota Singaraja: (Acuan Pengembangan Model Panduan Pengelolaan Laboratorium Kimia Berbasis Kearifan Lokal Tri Sakti. ISSN: 2303-288X , Volume 3, p. 2 